\title{
Prevalence of Gender-Based Violence and pregnancy outcome in Pregnant Women Attending Antenatal Clinic in Selected Primary Health Care Centres in Abuja FCT, Nigeria
}

\author{
Ayeni, Christabel Oyowo ${ }^{1,2 *}$, Yusuf, Oche ${ }^{2}$, Musa, Sarah Ojonogecha ${ }^{3}$ \\ ${ }^{1}$ Department of Public Health, Texila American University, Guyana \\ ${ }^{2}$ Institute of Human Virology, Nigeria (IHVN), Abuja \\ ${ }^{3}$ Zoology Department, Faculty of Natural Sciences, University of Jos, Nigeria
}

\begin{abstract}
Objective: The aim of the study was to determine the prevalence of Gender-based violence and pregnancy outcomes in pregnant women attending antenatal care clinics in two selected primary health care centres at Abuja FCT, Nigeria. Methodology: The descriptive and analytical cross-sectional research design and a convenience sampling method were used. A pretested semi-structured questionnaire with a Cronbach's alpha value of 0.77 was administered with the intervieweradministered data collection technique to collect data. The study population were pregnant women who attended antenatal clinic at the Primary Health Care Centres at Karu and Jikwoyi in Abuja-FCT; the sample size was 384 pregnant women between the ages of 15-44 years. Raw data generated from the completed questionnaire was analysed for simple frequency, percentage, and Chi-square analysis using the SPSS version 16. Results: Prevalence of GBV among the participants was 59.6\%, 99.4\% accounted for emotional abuse, physical abuse at $28.5 \%$, and sexual abuse at $13.6 \%$. The findings indicate that GBV single cases of emotional abuse was $66.7 \%$, physical abuse was $0.4 \%$, combined cases of emotional and physical violence were $19.3 \%$, emotional combined with sexual was $4.8 \%$, while the case of multiple violence of emotional, physical and sexual was $8.8 \%$. Overall, husbands were the perpetrators of the abuse and accounted for emotional abuse at $96.9 \%$, physical at $89.2 \%$, and sexual abuse at 100.0\%. Conclusion: The effect of physical abuse on pregnant outcome among pregnant women in their previous pregnancies was that $27.6 \%$ had a miscarriage, while $6.9 \%$ had preterm delivery.
\end{abstract}

Keywords: Gender-based violence, Nigeria, Pregnancy outcome.

\section{Introduction}

Gender-based violence is becoming a global pandemic, as it cuts across the globe, from Africa to America (North and South) to Asia to Australia and Europe, with increasing statistics by the day [1-5]. Several studies carried out on the prevalence of gender-based violence amongst pregnant women have reported prevalence of $35.9 \%$ of intimate partner violence (IPV) in at least one point in Life; $34.6 \%$ during pregnancy and observed that majority $97.1 \%$ of those reported to have experienced IPV during pregnancy were associated with psychological abuse, while physical and sexual violence accounted for a prevalence of $48.7 \%$ and $4.9 \%$ respectively [2].

Gurung and Acharya [6] studied the factors associated with gender-based violence among pregnant women attending antenatal care (ANC) in a cross-sectional study among 202 pregnant women using a semi-structured questionnaire with interviewer-administered data collection technique reported a high $91.1 \%$ prevalence of GBV amongst these women. Ramalingappa, Sowmya and Akhila [7] study on pregnant 
women in a tertiary care centre found out that of 635 pregnant women screened for intimate partner violence, $52.8 \%$ suffered one form of domestic violence or the other. Also, Malan, Spedding, and Sorsdahl [8], in their study, reported lifetime prevalence rates for any intimate partner violence as $44 \%$, the $12-$ months intimate partner violence as $32 \%$ for emotional and controlling behaviours, 29\% for physical and $20 \%$ for sexual abuse. Lencha, Ameya, Baresa, Minda, and Ganfure [9] in Ethiopia reported $33.0 \%$ and $36.3 \%$ for psychological and sexual violence, respectively, in pregnant women. Whereas Zheng, Zhu, Hu, Zhou, Yu, Yin, and $\mathrm{Xu}$ [10], in their study among pregnant women in urban communities of Hengyang City, China, reported $15.62 \%$ of domestic violence in at least once case during pregnancy; $11.07 \%$ mental violence; $0.98 \%$ physical. $0.86 \%$ sexual and $3.08 \%$ two different types of abuse.

Coming home to Nigeria prevalence of GBV among pregnant women, several studies abound, which included a study [11] at the University of Benin Teaching Hospital, Benin City, reported prevalence of $28.3 \%$ GBV during present pregnancy and $43.5 \%$ a year before current pregnancy. A study [12] at six private and public hospitals in 3 local government areas in Abuja, the Federal Capital Territory of Nigeria, depicted a prevalence $15 \%$ in current pregnancy, and husbands, partners, husband's relatives were the perpetrators of GBV among the pregnant women. Another study [13] carried out at antenatal clinic at University College Hospital $(\mathrm{UCH})$ and Adeoye maternity (AM), Ibadan South-West, Nigeria showed the prevalence of $17.1 \%$ during intimate pregnancy, partner were the perpetrators of GBV among the pregnant women. Orpin, Papadopoulos, and Puthussery [14] in their study reported that husbands were the most common perpetrators in 11 out of 17 reviews in Nigeria Onoh, Umeora, Ezeonu, Onyebuchi, Lawani, and Agwu [15] study at Antenatal clinics of Federal Medical Centre,
Abakaliki; Ebonyi state-reported prevalence of $44.6 \%$ in the index pregnancy. Iliyasu, Abubakar, Galadanci, Hayatu, and Aliyu [16] study at Aminu Kano Teaching Hospital, Kano reported a prevalence of $7.4 \%$ in the contemporary pregnancy, husbands, cowives, stepsons were the perpetrators of GBV among the pregnant women. Ashimi and Amole [17] determined the prevalence and predictors of domestic violence among 326 pregnant women in a health facility in Birmin kudu, Nigeria; they reported $34.3 \%$ during pregnancy, husbands and co-wives were the perpetrators of GBV among the pregnant women. According to Ishfaq, Malik, and Hussain [18], 83\% of respondents faced violence by their male partners, $87.5 \%$ of the respondents' husbands took drugs in a study by Ezeudu, Akpa, Waziri, Oladimeji, Adedire, Saude, Nguku, Nsubuga, and Fawole [19] it was reported that prevalence of intimate partner violence, a year before last pregnancy was $43.7 \%$ and during last pregnancy was $37.2 \%$. Oche, Adamu, Abubakar, Aliyu, and Dogondaji, [1] in their study intimate partner violence in pregnancy: knowledge and experiences of pregnant women and controlling the behaviour of male partners in Sokoto, Northwest Nigeria reported lifetime prevalence of intimate partner violence in pregnancy as $30.4 \%$; the most common forms of intimate partner violence were physical and sexual violence being $62.70 \%$ and $57.30 \%$, respectively. Besides, they reported that $55.7 \%$ of those who lived in rural areas experienced more intimate partner violence as against those living in urban areas.

Available literature on Gender-based violence against pregnant women in Nigeria shows most cases happen at the tertiary institution with an alarming rise [14]. Therefore, the aim of this study was to determine the prevalence of genderbased violence and pregnancy outcomes among pregnant women attending antenatal care clinics at PHCs at Abuja - FCT. Nigeria. To show that women in PHCs are also violated. 


\section{Methodology}

\section{Study Site}

Nigeria is a developing country with an area of $923769 \mathrm{~km}^{2}$. It is situated in Africa, bordering Niger to the North, Atlantic Ocean to the South, Benin Republic to the West and Cameroun to the East, Chad to North-East. Abuja is the capital city of Nigeria. Nigeria is divided into 36 states and FCT. The present study was carried out in Abuja FCT at two selected PHCS, Karu and Jikwoyi. Both towns are in AMAC (Abuia Metropolitan Area Council).

\section{Research Design}

The main objective for the present student was to determine the prevalence of gender-based violence, and pregnancy outcomes among pregnant women attending antenatal care clinics at two selected PHCs, namely Karu and Jkwoyi at Abuja-FCT. Nigeria. Therefore, a descriptiveanalytical study design was employed.

The questionnaire was designed to obtain information about the study objectives from respondents. The choice of using the questionnaire was based on the effectiveness of the instrument to get diverse opinions and views from the sampled respondents.

\section{Target Population}

The target population of this research was the pregnant women who attend antenatal clinics at the two selected PHCs at Karu and Jikwoyi at Abuja- FCT.

\section{Inclusion and Exclusion Criteria}

Pregnant women who participate in antenatal care at PHCS at Karu and JIkwoyi Abuja-FCT, Nigeria, who were willing to participate and filled the consent form, meet the inclusion criteria.

Pregnant women who do not attend antenatal care at PHCS at Karu and JIkwoyi were excluded from the study. Pregnant women who participate in the antenatal care clinic at PHCS at Karu and JIkwoyi, but were not willing to participate; met the exclusion criteria.

\section{Sampling Procedures}

The non-probability sampling method, particularly the convenient sampling method, was used [20, 21]. This is because there is prior knowledge of the population for the research; that is, the elements are already predefined, not everyone available was included for the study, but those who are available and met the defined criteria were included. Pregnant women attending antenatal clinics and who were willing to participate and completed the consent form met the inclusion criteria. It included married and unmarried women in the first, second, and third trimesters (all the respondents were captured only once during the study period when the health talk before seeing the doctor during the ANC visits. So long as they had not yet been admitted and come for |ANC and women between ages 15-44 years. For the respondents who were between 15 and 18 years, both their consent and their guardian/parent's consent were sought in accordance with the guidelines of the Federal Ministry of Health [22].

\section{Sample Size Determination}

Determining a suitable sample size in an experiment is a significant step towards achieving a numerical approach to the research. The correct sample size will enable the research to get reliable data. The sample size is the number of individuals in the research population. The larger the sample size, the larger the precision hence for a given power for a specific research design to detect an effect of a given size. The sample size was estimated according to the formula given by Taherdoost [23]. Using the Equation below:

$$
n=p(100-p) Z^{2} / E^{2}
$$

where:

$\mathrm{n}=$ required sample size

$\mathrm{p}=$ percentage occurrence of gender violence among pregnant women, in this case, $50.9 \%$ approximated to $50.0 \%$ [18]

$\mathrm{E}=$ percentage maximum error required, which is $5 \%$ 
$\mathrm{Z}=$ the value corresponding to the level of confidence interval required, which is 1.96 Substituting in the equation above

$$
\mathrm{n}=50(100-50) 1.96 * 1.96 / 5 * 5=384
$$

The sample size was 384 .

\section{Measurement Instrument}

The measurement instrument constituted a semi-structured questionnaire that was administered to eligible pregnant women. The questionnaire included questions on demography, socioeconomic and gender-based violence, with the interviewer-administered data collection technique (This method of administration was adopted so that the researcher would be available to explain points the respondents cannot interpret). It is made up of items grouped into three sections: A, B, and C. Section A contain ten details meant to generate information on the respondents' demography; Section B is made up of four-item questions intended to produce data on the husband/ partner demography; Section $\mathrm{C}$ is made up of sixteen item questions designed to generate data on violence from husband to wife. The abuse assessment screening tool (AAS Tools) and HITS tools were used in this research $[24,25,26]$.

\section{Methods of Data Collection}

Data for the research were collected from the primary source. The primary data were collected using a questionnaire to gather raw data and first-hand information from the population. The questionnaire was designed using the available literature to measure the respondents' opinions about gender-based violence they have experienced. The semi-administered structured questionnaire was used to collect the data from the two selected PHCS, Karu and Jikwoyi, Abuja-FCT, Nigeria. The data collection took place in a period of 4 weeks; the questionnaire was administered to 95 pregnant women per week in order to get the required sample size of 384 pregnant women.

\section{Validity and Reliability of Instrument}

In order to ensure that a questionnaire provides the researcher with the information being sought, it was ensured that it was reliable, valid, and as short as possible to encourage a high response rate. The validity of a questionnaire is the degree to which it accurately measures what it purposes to measure.

The questionnaire was pre-tested to establish the face validity of the items. The pre-test aimed to prevent any vagueness and misunderstanding. Then the revised questionnaire was then administered to participants. The pregnant women had data collected with the intervieweradministered data collection technique. The reliability of the instrument was ensured by a pilot study of the questionnaires and which was then used for the study. Face validity of the research instrument was ensured by using simple English language and clearly stated items in the questionnaires.

\section{Ethical clearance}

The study procedures followed that of WHO 2001 [27] Ethical Safety Recommendations for research on domestic violence against women. There were minimal psychological risks in participating in the study by asking women to recall acts of violence perpetrated against them. The interview was conducted in a private space at the clinics.

During the recruitment process, women were informed about the study aim and were told that their participation in the study was voluntary and could withdraw their participation at any time regarded necessary by them-ethical clearance and permission to do the research sought from the AMAC Abuja FCT. Confidentiality was maintained by omitting the names or identities of individuals interviewed on the questionnaires.

A pilot study was undertaken to identify the strengths and weaknesses in the research questionnaire. Besides, the feasibility of the study, adequacy of the research design, as well as study method, assessed. Content validity was obtained from two sources, the literature review 
and representatives of the population of pregnant women.

\section{Data description/Analysis}

The participants were pregnant women attending the antenatal clinic at the selected PHCs. However, copies of the questionnaire were administered to pregnant women that were willing to participate. The Statistical analysis was carried out by the use of SPSS statistical software. The various socio-demographic status of the participants identified from the questionnaire. Descriptive statistics such as frequency and percentages and Chi-square were used for the prevalence study.

The raw data were edited to detect errors and omissions, after which corrections were made, and coding was done by assigning a number of the responses so that the participants were put into categories. After the coding, classification and tabulation were carried out. Data were classified based on socio-demographic characteristics such as age, religion, educational background, and other collective responses. The data was analyzed using SPSS version 16.0. socio-demographic variables summary was done using frequencies and percentages. The questionnaire was analyzed for reliability and internal consistency before pre-testing. Cronbach's alpha value was 0.77 , which indicates a high level of internal consistency of the questions (more than the acceptable level of $0.7)$.

\section{Results}

\section{Socio-demographic Characteristics of the Study Participants}

Table 1 showed the socio-demographic characteristics of study participants; under the thematic section age, Karu PHC participants age range 25-34 years were the highest number which was $57.1 \%$, while the Jikwoyi age range of 15-25 years old had the highest number with $49.2 \%$. Figure 1 graphically shows the age distribution of the study participants in the two PHCS, Karu and Jiwkoyi, Abuja- FCT. The majority of the study population were the 25-34 years age group.

The thematic section educational level which showed Karu PHC had participant with secondary education the highest group with 44.1\%; while Jikwoyi had $50.0 \%$ most top participant with secondary educational level. The thematic heading reading and writing status, Karu PHC reading and writing status was the highest group which was $75.8 \% \%$, Jikwoyi also had secondary educational level as highest with $50.0 \%$. The thematic heading religion, for Karu PHC Christian, were the highest group with 64.1\% while Jikwoyi had Christian as $60.9 \%$ highest. The thematic heading marital status Karu PHC it showed that the married was the highest group with $95.7 \%$ while Jikwoyi the married had $96.1 \%$ being the most top group.

The thematic heading years of marriage; it showed that Karu PHC 1-5 years of marriage was the highest group with $33.6 \%$, while Jikwoyi had $30.5 \%$ being the most top group. The thematic heading occupation showed that for Karu PHC, the highest occupation group were the unemployed with $44.9 \%$, while Jikwoyi had $69.5 \%$ being the most top group. The thematic heading income showed that for Karu PHC participants with no income were the highest group with $42.4 \%$, while Jikwoyi had $71.1 \%$. The thematic heading more educational levels than the husband; it showed that for Karu PHC participants, only $2.7 \%$ had more educational level than their husband, while Jikwoyi were $3.1 \%$ more education than their husband. The thematic heading earns more money than the husband; for Karu PHC participants, only $2.3 \%$ had more educational level than their husband, while Jikwoyi, who were $0.8 \%$, had more education than their husband.

\section{Prevalence of GBV in the Study}

The overall prevalence of GBV in this study was $59.6 \%$, as seen in Table 2. Table 3 depicts the prevalence of GBV among women who had experienced GBV based on type. Overall 
emotional abuse was the most common GBV reported; this accounted for $99.4 \%$, followed by physical abuse $28.5 \%$, while sexual abuse was $13.6 \%$ the least. In the past 12 months, participants hit, slapped, kicked, hurt 13.2\%. During pregnancy, overall being hit, slap, kick, hurt was $12.7 \%$. In the past 12 months of sexual abuse, overall, sexual abuse was $3.1 \%$. Sexual abuse overall was $13.6 \%$. The prevalence of participants scared of anyone was $13.8 \%$ overall. Figure 2 shows the overall prevalence of GBV in both Karu and Jikwoyi of about $60 \%$.

Figure 3 depicts the distribution of occurrence of a type of violence among the participants. The highest GBV was single cases of emotional abuse at $66.7 \%$, one instance of physical abuse of $0.4 \%$, combined case of emotional and physical violence was $19.3 \%$, emotional combined with sexual was $4.8 \%$ while the case of multiple violence of emotional, physical and sexual was $8.8 \%$.

Table 4 depicts the perpetrator of the various abuse on participant in the study. Overall, 96.9\% of the participants reported that husbands were the perpetrators of emotional abuse accounted, $89.2 \%$ reported that husbands were physical abuse perpetrators, $100 \%$ of participants said husbands were the culprits of sexual abuse. In the past 12 months, overall being hit, slap, kick, hurt was $74.2 \%$. During pregnancy, overall being hit, slap, kick, hurt was $86.2 \%$. In the past 12 months, sexual abuse overall was $85.7 \%$. Generally, the prevalence of participants being scared of anyone was $98.0 \%$.

Table 5 depicts the effects of the prevalence of physical abuse on the pregnancy of women who were abused during a previous pregnancy. The majority $(65.5 \%)$ of pregnant women physically abused during pregnancy reported no effect on the outcome of their pregnancies. However, $27.6 \%$ had a miscarriage, while the remaining $6.9 \%$ had preterm delivery. Table 6 elucidate causes of violence among the participants, and it shows that alcoholic partner is one of the major causes of GBV among participants.

\section{Discussions}

In the present study, the overall prevalence of GBV was $59.6 \%$ the prevalence of GBV among participating women, and this is almost in agreement with the study of Ramalingappa, Sowmya, \& Akhila [7], who reported a prevalence of $52.8 \%$.

Among participants who reported experience GBV, overall emotional abuse was the most common GBV reported prevalence accounted for $99.4 \%$, followed by physical abuse $28.5 \%$, while sexual abuse was $13.6 \%$, the least. This result almost corroborates the study of Okada, Hoga, Borges, Albuquerque \& Belli [2] prevalence of $97.1 \%$ psychological violence, $48.7 \%$ reported physical abuse, and $4.9 \%$ experiencing sexual violence.

In the present study prevalence of physical violence in the past 12 months (participant being hit, slap, kick, hurt) was $13.2 \%$, while sexual abuse overall was $3.1 \%$ which are lower than the values in the study of Rahman, Houque \& Makinoda [28] who reported prevalence intimate partner violence among married women in the last 12 months before their study as $19.4 \%$ and $10.5 \%$ for physical and sexual respectively.

Overall, husbands/partners were the perpetrators; emotional abuse prevalence was $96.9 \%$, physical abuse overall prevalence was $89.2 \%$ sexual abuse was $100.0 \%$. Adesina, Oyugbo, and Olubukola [13] also depict that intimate partner were the perpetrators of GBV among pregnant women. In the study of Orpin, Papadopoulos, \& Puthussery [14], husbands were the most common perpetrators in 11 out of 17 reviews in Nigeria.

In the present study, $98.0 \%$ of participants reported being scared of anyone were frightened of their husband, and this was a lot higher than the study of Vakili, Nadrian, Fathipoor, Boniadi, and Morowatisharifabad [29]. They reported a prevalence of $31.9 \%$ being afraid of their husbands.

The effect of physical abuse on pregnant outcomes shows that $27.6 \%$ had a miscarriage in a previous, while $6.9 \%$ had preterm delivery. 
The pregnancy outcome reported in the study was a previous pregnancy of the participants, not the pregnancy of the present; premature rupture of membranes, urinary infections, and vaginal bleeding have been presented as outcomes of GBV among pregnant women. [30].

Table 1. Socio-demographic Characteristics of Study Participants

\begin{tabular}{|c|c|c|c|c|c|}
\hline \multirow[t]{3}{*}{ Variable } & \multicolumn{2}{|l|}{ PHC } & \multirow{3}{*}{$\begin{array}{l}\text { Total }=384 \\
\text { Frequency }(\%)\end{array}$} & \multirow[t]{3}{*}{$\mathbf{X}^{2}$} & \multirow[t]{3}{*}{ P-value } \\
\hline & \multirow{2}{*}{\begin{tabular}{|l|} 
Karu $=256$ \\
Frequency $(\%)$ \\
\end{tabular}} & \multirow{2}{*}{$\begin{array}{l}\text { Jikwoyi=128 } \\
\text { Frequency }(\%)\end{array}$} & & & \\
\hline & & & & & \\
\hline \multicolumn{4}{|l|}{ Age (years) } & 26.409 & $<0.001 *$ \\
\hline $15-24$ & $72(28.1)$ & $70(54.7)$ & $142(37.0)$ & & \\
\hline $25-34$ & $146(57.1)$ & $43(33.6)$ & $189(49.2)$ & & \\
\hline $35-44$ & $38(14.8)$ & $15(11.7)$ & $53(13.8)$ & & \\
\hline \multicolumn{5}{|l|}{ Education } & $0.181^{\#}$ \\
\hline None & $35(13.7)$ & $28(21.9)$ & $63(16.4)$ & & \\
\hline Primary & $31(12.1)$ & $8(6.21)$ & $39(10.2)$ & & \\
\hline Vocational & $3(1.2)$ & $1(0.8)$ & $4(1.0)$ & & \\
\hline Secondary & $113(44.1)$ & $64(50)$ & $177(46.1)$ & & \\
\hline Tertiary & $74(28.9)$ & $27(21.1)$ & $101(26.3)$ & & \\
\hline \multicolumn{5}{|c|}{ Reading and writing status } & $0.331^{\#}$ \\
\hline Read and write & $194(75.8)$ & $92(71.9)$ & $286(74.5)$ & & \\
\hline Only read & $2(.8)$ & $0(.0)$ & $2(.5)$ & & \\
\hline Only write & $2(.8)$ & $0(.0)$ & $2(.5)$ & & \\
\hline None & $58(22.7)$ & $36(28.1)$ & $94(24.5)$ & & \\
\hline \multicolumn{5}{|l|}{ Religion } & $0.947^{\#}$ \\
\hline Christianity & $164(64.1)$ & $78(60.9)$ & $242(63.0)$ & & \\
\hline Islam & $88(34.4)$ & $50(39.1)$ & $138(35.9)$ & & \\
\hline Paganism/ Atheist & $4(1.5)$ & $0(.0)$ & $4(1.1)$ & & \\
\hline \multicolumn{4}{|l|}{ Marital status } & & $0.377^{\#}$ \\
\hline Single & $6(2.3)$ & $4(3.1)$ & $10(2.6)$ & & \\
\hline Married & $245(95.7)$ & $123(96.1)$ & $368(95.8)$ & & \\
\hline divorced & $5(2.0)$ & $1(.8)$ & $6(1.6)$ & & \\
\hline \multicolumn{5}{|c|}{ Years of marriage (years) } & $0.861^{\#}$ \\
\hline$<1$ & $71(27.7)$ & $40(31.2)$ & $111(28.9)$ & & \\
\hline $1-5$ & $86(33.6)$ & $39(30.5)$ & $125(32.6)$ & & \\
\hline $6-10$ & $73(28.5)$ & $33(25.8)$ & $106(27.6)$ & & \\
\hline More than 10 & $20(7.8)$ & $12(9.4)$ & $32(8.3)$ & & \\
\hline $\begin{array}{l}\text { Not applicable (Not } \\
\text { married) }\end{array}$ & $6(2.4)$ & $4(3.1)$ & $10(2.3)$ & & \\
\hline \multicolumn{5}{|l|}{ Occupation } & $<0.001$ *\# \\
\hline Unemployed & $115(44.9)$ & $89(69.5)$ & $204(53.1)$ & & \\
\hline Labourer & $8(3.1)$ & $1(.8)$ & $9(2.3)$ & & \\
\hline Artisan & $4(1.6)$ & $0(.0)$ & $4(1.0)$ & & \\
\hline Small business / trading & $84(32.8)$ & $28(21.9)$ & $112(29.2)$ & & \\
\hline Farming & $1(.4)$ & $0(.0)$ & $1(.3)$ & & \\
\hline Civil / Public Servant & $8(3.1)$ & $5(3.9)$ & $13(3.4)$ & & \\
\hline
\end{tabular}




\begin{tabular}{|l|l|l|l|l|l|}
\hline Others & $36(14.1)$ & $5(3.9)$ & $41(10.7)$ & & \\
\hline Income(N) & $86(33.7)$ & $19(14.8)$ & $105(27.4)$ & & \\
\hline$<20,000$ & $35(13.7)$ & $5(3.9)$ & $40(10.4)$ & & \\
\hline $20,001-50,000$ & $11(4.3)$ & $8(6.2)$ & $19(5.0)$ & & \\
\hline $50,001-100,000$ & $10(3.9)$ & $5(3.9)$ & $15(3.9)$ & & \\
\hline $100,001-200,000$ & $108(42.4)$ & $91(71.1)$ & $199(52.0)$ & & \\
\hline None & $5(2.0)$ & $0(.0)$ & $5(1.3)$ & & \\
\hline I do not want to say & $7(2.7)$ & $4(3.1)$ & $11(2.9)$ & & \\
\hline More educated than the husband & $124(96.9)$ & $366(95.3)$ & & \\
\hline Yes & $242(94.5)$ & $0(.0)$ & $5(1.3)$ & \\
\hline No & $5(2.0)$ & $0(.0)$ & $2(.5)$ & \\
\hline I do not know & $2(.8)$ & & & \\
\hline I do not want to tell & $6(2.3)$ & $1(.8)$ & $7(1.8)$ & \\
\hline Earn more money than the husband & $229(89.5)$ & $118(92.2)$ & $347(90.4)$ & & \\
\hline Yes & $19(7.4)$ & $9(7.0)$ & $28(7.3)$ & & \\
\hline No & $2(.8)$ & $0(.0)$ & $2(.5)$ & \\
\hline I do not know & & & \\
\hline I do not want to tell &
\end{tabular}

$*=$ Significant $=$ Adjusted $\mathrm{X}^{2}$

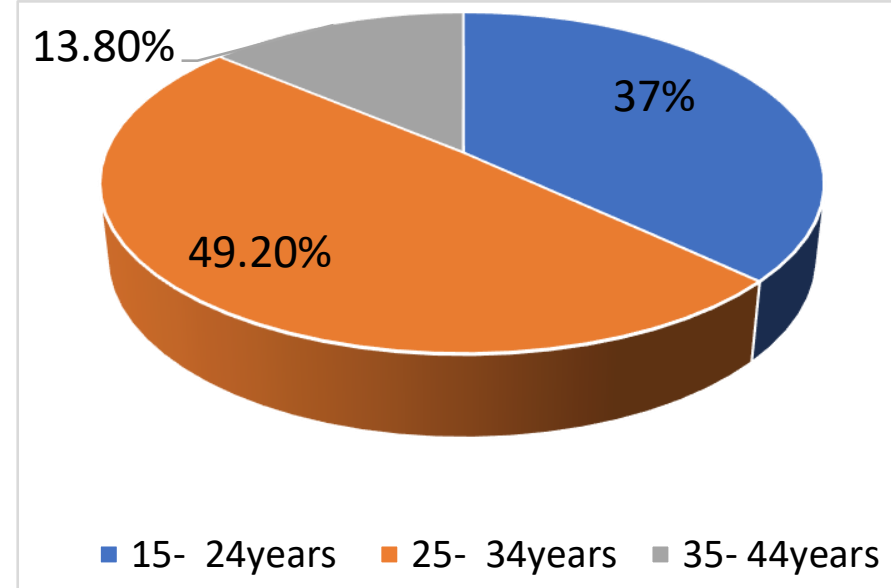

Figure 1. Age Distribution of Study Participants

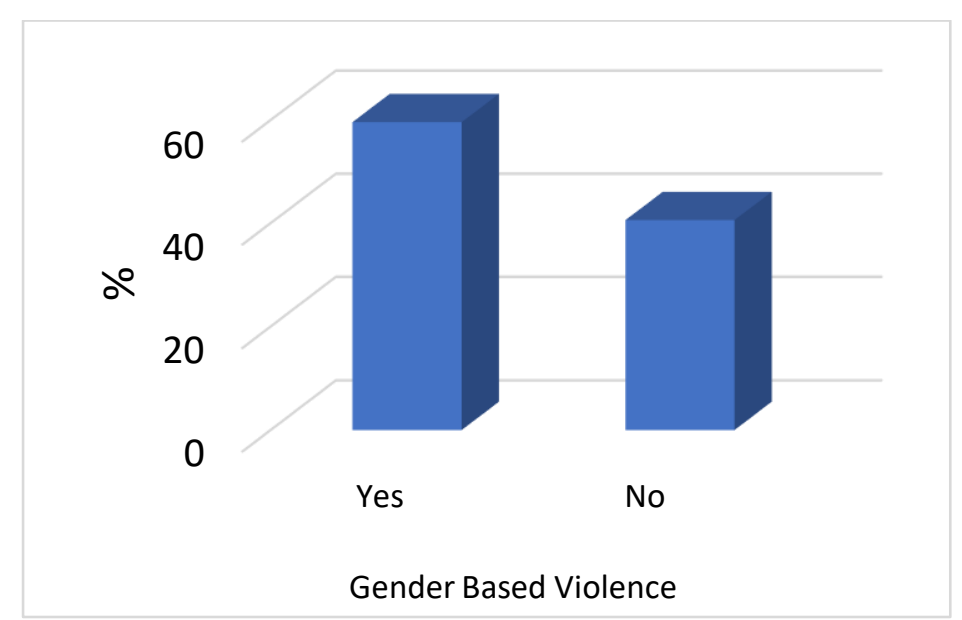

Figure 2. Overall Prevalence of GBV in both Karu and Jikwoyi 
Table 2. Prevalence of GBV in the Participating Women

\begin{tabular}{|l|l|l|l|l|l|}
\hline \multirow{2}{*}{ GBV } & \multicolumn{2}{|l|}{ PHC } & Total =384 & \multirow{2}{*}{$\mathbf{X}^{\mathbf{2}}$} & \multirow{2}{*}{ P-value } \\
\cline { 2 - 4 } & Karu =256 & Jikwoyi= 128 & Frequency (\%) & & \\
\cline { 2 - 4 } & Frequency (\%) & Frequency (\%) & & & \\
\hline Yes & $149(58.2)$ & $79(61.7)$ & $228(59.6)$ & 0.437 & 0.508 \\
\hline No & $107(41.8)$ & $49(38.3)$ & $156(40.6)$ & & \\
\hline Total & $256(66.7)$ & $128(33.3)$ & $384(100.0)$ & & \\
\hline
\end{tabular}

Table 3. Prevalence of GBV among Women who had Experienced GBV based on the Type

\begin{tabular}{|c|c|c|c|c|c|}
\hline \multirow[t]{3}{*}{ Variable } & \multicolumn{2}{|l|}{ PHC } & \multirow{3}{*}{$\begin{array}{l}\text { Total }=228 \\
\text { Frequency }(\%)\end{array}$} & \multirow[t]{3}{*}{$\mathbf{X}^{2}$} & \multirow[t]{3}{*}{ P-value } \\
\hline & \multirow{2}{*}{\begin{tabular}{|l|} 
Karu =149 \\
Frequency $(\%)$ \\
\end{tabular}} & \multirow{2}{*}{$\begin{array}{l}\text { Jikwoyi=79 } \\
\text { Frequency (\%) }\end{array}$} & & & \\
\hline & & & & & \\
\hline \multicolumn{5}{|c|}{ Emotional or Psychological Abuse } & $>0.999^{\#}$ \\
\hline Yes & $148(99.3)$ & $79(100.0)$ & 227(99.6) & & \\
\hline No & $1(0.7)$ & $0(0.0)$ & $1(0.4)$ & & \\
\hline \multicolumn{4}{|c|}{ Physical abuse } & 0.671 & 0.413 \\
\hline Yes & $47(31.5)$ & $18(26.1)$ & $65(28.5)$ & & \\
\hline No & $102(68.5)$ & $51(73.9)$ & $153(71.5)$ & & \\
\hline \multicolumn{4}{|c|}{ In past 12 months Hit slap kick hurt } & 2.203 & 0.138 \\
\hline Yes & $16(10.7)$ & $14(17.7)$ & $30(13.2)$ & & \\
\hline No & $133(89.3)$ & $65(82.3)$ & $198(86.8)$ & & \\
\hline \multicolumn{4}{|c|}{ Hit during pregnancy } & 14.306 & $0.001 *$ \\
\hline Yes & $11(7.4)$ & $18(26.1)$ & $29(12.7)$ & & \\
\hline No & $138(92.6)$ & $51(73.9)$ & $199(87.3)$ & & \\
\hline \multicolumn{5}{|c|}{ In the past 12 months sexual abuse } & $0.426^{\#}$ \\
\hline Yes & $6(4.0)$ & $1(1.3)$ & $7(3.1)$ & & \\
\hline No & $143(96.0)$ & $78(98.7)$ & $221(96.9)$ & & \\
\hline \multicolumn{5}{|c|}{ Scared anyone } & $<0.001 *^{\#}$ \\
\hline Yes & $45(30.2)$ & $3(3.8)$ & $48(21.0)$ & & \\
\hline No & $104(69.8)$ & $76(96.2)$ & $180(79.0)$ & & \\
\hline \multicolumn{4}{|c|}{ Sexual abuse } & 6.656 & $0.013^{*}$ \\
\hline Yes & $15(10.1)$ & $16(23.2)$ & $31(13.6)$ & & \\
\hline No & $234(89.9)$ & $53(86.8)$ & 197(86.4) & & \\
\hline
\end{tabular}

$*=$ Significant $=$ Adjusted $\mathrm{X}^{2}$

Table 4. Perpetrator of the Abuse

\begin{tabular}{|l|l|l|l|l|l|}
\hline \multirow{2}{*}{ GBV } & \multicolumn{2}{|l|}{ PHC } & Total =384 & \multirow{2}{*}{$\mathbf{X}^{\mathbf{2}}$} & \multirow{2}{*}{ P-value } \\
\cline { 2 - 3 } & Karu =256 & Jikwoyi=128 & \multirow{2}{*}{ Frequency (\%) } & & \\
\cline { 2 - 3 } & Frequency (\%) & Frequency (\%) & & \\
\hline Emotional or psychological abuse & $220(96.9)$ & & \\
\hline Husband & $145(98.0)$ & $75(94.9)$ & $7(3.1)$ & & \\
\hline Boyfriend & $3(2.0)$ & $4(5.1)$ & & \\
\hline Physical abuse & $14(77.8)$ & $58(89.2)$ & & \\
\hline Husband & $44(93.6)$ & & & \\
\hline
\end{tabular}




\begin{tabular}{|c|c|c|c|c|}
\hline Boyfriend & $3(6.4)$ & $4(22.2)$ & $7(10.8)$ & \\
\hline \multicolumn{4}{|c|}{ Hit slap kick hurt } & $>0.999^{\#}$ \\
\hline Husband & $13(76.5)$ & $10(71.4)$ & $23(74.2)$ & \\
\hline Boyfriend & $4(23.5)$ & $4(28.6)$ & $8(25.8)$ & \\
\hline \multicolumn{4}{|c|}{ Hit during pregnancy } & $0.268^{\#}$ \\
\hline Husband & $11(100.0)$ & $14(77.8)$ & $25(86.2)$ & \\
\hline Boyfriend & $0(0.0)$ & $4(22.2)$ & $4(13.8)$ & \\
\hline \multicolumn{4}{|c|}{ Forced intercourse } & $>0.999^{\#}$ \\
\hline Husband & $5(83.3)$ & $1(100.0)$ & $6(85.7)$ & \\
\hline Boyfriend & $1(16.7)$ & $0(0.0)$ & $1(14.3)$ & \\
\hline \multicolumn{4}{|c|}{ Scared of anyone } & $>0.999^{\#}$ \\
\hline Husband & $44(97.8)$ & $3(100.0)$ & $47(98.0)$ & \\
\hline Boyfriend & $1(2.2)$ & $0(0.0)$ & $1(2.0)$ & \\
\hline \multicolumn{4}{|c|}{ Sexual abuse } & $1.000^{\#}$ \\
\hline Husband & $16(100.0)$ & $16(100.0)$ & $32(100.0)$ & \\
\hline Boyfriend & $0(.0)$ & $0(.0)$ & $0(.0)$ & \\
\hline
\end{tabular}

$*=$ Significant $=$ Adjusted $\mathrm{X}^{2}$

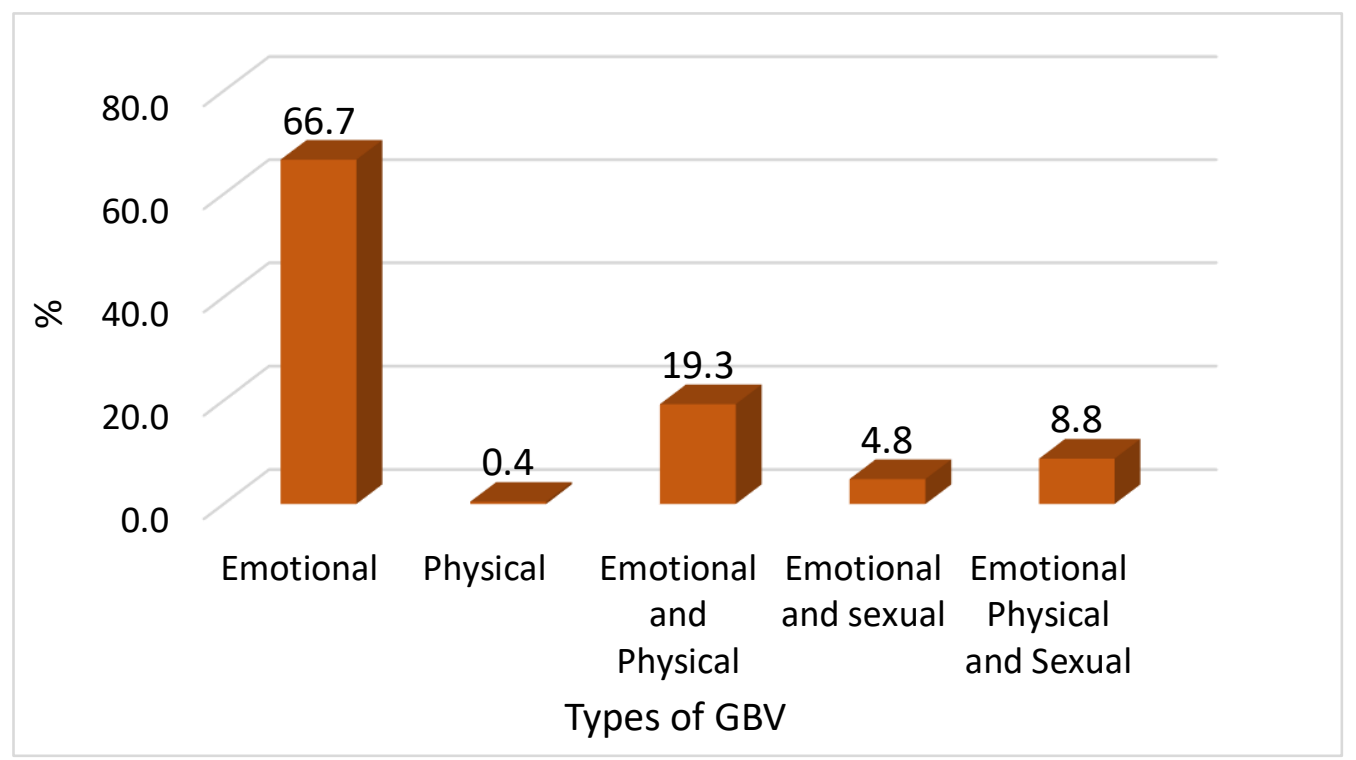

Figure 3. Types of Gender-Based Violence Reported in the Study

Table 5. Effect of Physical Abuse on Pregnant Women during a Previous Pregnancy

\begin{tabular}{|l|l|l|l|l|}
\hline Effect of abuse on pregnancy & Karu & JIkwoyi & Total & p-value \\
\hline No effect & $4(36.4)$ & $15(83.3)$ & $19(65.5)$ & \multirow{2}{*}{$0.015^{*}$} \\
\hline Miscarriage & $5(45.5)$ & $3(16.7)$ & $8(27.6)$ & \\
\hline Premature delivery & $2(18.2)$ & $0(0)$ & $2(6.9)$ & \\
\hline Total & $11(37.9)$ & $18(62.1)$ & $29(100.0)$ & \\
\hline
\end{tabular}


Table 6. Causes of Violence among abused Pregnant Women

\begin{tabular}{|l|l|l|}
\hline Variable & Frequency & \% \\
\hline Alcoholic partner & 65 & 28.5 \\
\hline Unemployed partner & 9 & 3.9 \\
\hline Partner's gambling lifestyle & 2 & 0.9 \\
\hline Partner's extramarital affair & 11 & 4.8 \\
\hline Partner is listening to other family relatives & 8 & 3.5 \\
\hline Partners' very high sexual libido & 10 & 4.4 \\
\hline Lack of respect and communication & 43 & 18.9 \\
\hline Not having a male child & 8 & 3.5 \\
\hline Others & 72 & 31.6 \\
\hline Total & 228 & 100.0 \\
\hline
\end{tabular}

\section{Conclusions}

The age characteristics of study participants age, Karu PHC participant age range 25-34 years were the highest number which was $57.1 \%$, while Jikwoyi age range of 15-25 years old had the highest number with $49.2 \%$.

The effect of physical abuse on pregnant women during pregnancy shows that $27.6 \%$ had a miscarriage, while $6.9 \%$ had preterm delivery in previous pregnancies, further studies to monitor women from start to end of pregnancy or in at least two of their pregnancies to conclude on pregnancy outcome due to physical abuse.

\section{Recommendations}

Based on the findings of the study and the conclusions made, the following recommendation is made.

1) Routine screening for intimate partner violence among pregnant women and counselling during clerking of pregnant women on their first ANC visit in every pregnancy to probe who are being emotionally, physically, sexually abused.

2) Since husbands are the primary culprit of GBV in pregnancy, husbands should be encouraged to come on antennal visits with their wives so that they would be counsel on how to care for their wives, especially when pregnant.

3) There is an urgent need for relevant stakeholders to institute measures to reduce domestic violence in women, whether pregnant or not.

\section{Acknowledgment}

Our thanks go to the management of AMAC, Primary Health Centres Karu, and Jukwoyi, Abuja -FCT.

Our thanks also go to the participants for agreeing to participate in the study.

The article is part of Mrs. Christabel Oyowo Ayeni research for her Masters programe in Public Health from Texila American University, Guyana

\section{Declaration of conflicting Interests}

The authors(s) declared no potential conflicts with respect to the research, authorship, and/or publication of this article. 


\section{References}

[1] Oche, O.M., Adamu, H., Abubakar, A., Aliyu, M. S., \& Dogondaji, A. S. (2020) Intimate Partner Violence in Pregnancy: Knowledge and Experiences of Pregnant Women and Controlling Behavior of Male Partners in Sokoto, Northwest Nigeria. International Journal of Reproductive Medicine Volume 2020, Article ID 7626741, https://doi.org/10.1155/2020/7626741.

[2] Okada, M. M., Hoga, L. A. K., Borges, A. L. V, Albuquerque, R. S., \& Belli, M. A (2015). Domestic violence against pregnant women. Acta Paul Enferm. 28(3),270-4 http://dx.doi.org/10.1590/19820194201500045 .

[3] Chaves, K, Eastwood, J., Ogbo, F. A., Hendry, A., Jalaludin, B., Khanlari, S., and Page, A. Itimate partner violence identified through routine antenatal screening and maternal and perinatal health outcomes. BMC Pregnancy and Childbirth (2019) 19:357 https://doi.org/10.1186/s12884-019-2527-9.

[4] Puccia, M. I. R., Mamede, M. V. and deSoula, L. (2018). Intimate partner violence and postpartum women in Sao Paulo, Brazil. Journal of Human Growth and Development 28(2). http://dx.doi.org/10.7322/jhgd/147218.

[5] Izguirre, A and Calvete, E. (2014). Intimate partner violence during pregnancy: women's narrative about their mothering experiences. Psychosocial Intervention, 23, 209-215.

[6] Gurung, S \& Acharya, J. (2015). Factor Influencing Gender-Based Violence among Pregnant Women Attending Antenatal Clinic in PHC of Syangja District, Nepal. Makara Journal of Health Research, 2015, 19(3): 99-103. Doi: 10.7454/msk. v19i3.5640.

[7] Ramalingappa, P., Sowmya, K.P., \& Akhila, M.P. (2017). Factor affecting intimate partner violence among Pregnant Women in a Tertiary care centre NJOG, 12(2), 52- 57.

[8] Malan, M., Spedding, M. F., \& Sorsdahl, K (2018). The prevalence and predictors of intimate partner violence among pregnant women attending a midwife and obstetrics unit in the Western Cape. Global Mental Health, retrieved from https://www/cambrigdeorg/core on 06/06/2019. DOI:10.1017/gmh.2018.9
[9] Lencha, B., Ameya, G., Baresa, G., Minda, Z., \& Ganfure, G. (2019). Intimate partner violence and its associated factors among pregnant women in Bale Zone, Southeast Ethiopia: A cross-sectional study. PloS one, 14(5), e0214962.

[10]Zheng, B., Zhu, X., Hu, Z., Zhou, W., Yu, Y., Yin, S., \& Xu, H (2020). The prevalence of domestic violence and its correlation with family factors: A cross-sectional study among pregnant women in urban communities of Hengyang City, China BMC Public Health (2020) 20,620 https://doi.org/10.1186/s12889-020-08683-9.

[11] Olagbuji, B., Ezeanochie, M., Ande, A., \& Ekaete, E. (2010). Trends and determinants of pregnancy-related domestive violence in a referral centre in southern Nigeria. International journal of gynecology\& obstretics 108,101-103.

[12] Arulogun, O. S., \& Jidda, K. A. (2011). Experiences of violence among pregnant women attending antenatal clinics in selected hospitals in Abuja, Nigeria. Sierra Leone Journal of Biomedical Research, 3(1), 43-48.

[13] Adesina, O., Oyugbo, I. \& Olubukola, A. (2011). Prevalence and pattern of violence in pregnancy in Ibadan, South-west, Nigeria. Journal of Obstetrics and Gynaecology, 31 (3), 232-236.

[14] Orpin, B. J., Papadopoulos, C., \& Puthussery, S. (2013). The prevalence of domestic violence among pregnant women in Nigeria: a systemic review. Trauma, Violence \& Abuse, 21 (1),3-15. https://doi.org/10.1177/1524838017731570.

[15] Onoh, R. C., Umeora, O. U. J., Ezeonu, P. O., Onyebuchi, A. K., Lawani, O. L., \& Agwu, U. M. (2013). Prevalence, pattern and consequences of intimate partner violence during pregnancy at Abakaliki Southeast Nigeria. Annals of Medical and Health Sciences Research, 3(4), 484-491.

[16] Iliyasu, Z., Abubakar, I. S., Galadanci, S. H., Hayatu, Z., \& Aliyu, M. H. (2013). Prevalence and risk factors for domestic violence among pregnant women in Northern Nigeria. Journal of Interpersonal Violence, 28(4), 868-883. Doi: $10.1177 / 0886260512455872$.

[17] Ashimi, A. O., \& Amole, T.G. (2015). Prevalence and predictors for domestic violence among pregnant women in a rural community 
Northwest, Nigeria. Nigeria Medical Journal: Journal of the Nigeria Medical Association, 56(2), 118-121.

[18] Ishfaq, K., Malik, R., \& Hussain, S. (2018). Contributing Factors of Domestic Violence against Women: A Study of Dar-Ul-Aman, District Multan, Pakistan. Pakistan Journal of Criminology, 10(4), 3041.

[19] Ezeudu, C.C., Akpa, O., Waziri, N. E., Oladimeji, A., Adedire, E., Saude, I., Nguku, P., Nsubuga, P., \& Fawole, O. I (2019). Prevalence and correlates of intimate partner violence, before and during pregnancy among attendees of maternal and child health services, Enugu, Nigeria: mixed-method approach, January 2015. PAMJ Supplement Vol 32(1), 14 10.11604/pamj.supp.2019.32.113289.

[20]Alvi, M. (2016). A Manual for Selecting Sampling Techniques in Research. https://mpra.ub.uni-muenchen.de/70218/. Retrieved 12/08/2019.

[21] Taherdoost, H. (2016). Sampling Methods in Research Methodology; How to choose a sampling technique for research. International Journal of Academic Research in Management (IJARM), 5 (2), 18-27.

[22]Federal Ministry of Health (FMoH). (2014). Guidelines for Young Persons' Participation in Research and Access to Sexual and Reproductive Health Services in Nigeria. A publication of Federal Ministry of Health.

[23] Taherdoost, H. (2017). Determining Sample Size; How to Calculate Survey Sample Size International Journal of Economics and Management Systems, 2 , 237-239.
[24]Centres for Disease Control and Prevention (2009). Intimate partner violence during pregnancy: A guide for clinicians. Retrieved on $18^{\text {th }}$ November 2019.http://www.cdc.gov/reproductivehealth/violenc e/intimatepartnerviolence.

[25] Sherin K.M, Sinacore J.M, Li XQ, Zitter, R. E., Shakil, A (1998). HITS: a short domestic violence screening tool for use in a family practice setting. Family Medicine; 30(7), 508-512.

[26] Soeken KL, McFarlane J, Parker B., \& Lominack MC. (1998). The abuse assessment screen: a clinical instrument to measure frequency, severity, and perpetrator of abuse against women. In: JC Campbell, ed. Empowering Survivors of Abuse: Health Care for Battered Women and Their Children. Thousand Oaks, CA: Sage Publications; 1998:195-203.

[27] World Health Organization (WHO), 2001 Ethical and safety recommendations for researching, documenting and monitoring sexual violence in emergencies.

[28] Rahman, M., Hoque, M.A., \& Makinoda, S. (2011). Intimate partner violence against women: is women empowerment a reducing factor? A study from a national Bangladeshi sample. Journal of Family Violence, 26,411- 420.

[29] Vakili, M., Nadrian, H., Fathipoor, M., Boniadi, Morowatisharifabad, M. A.Prevalence and Determinants of Intimate Partner Violence Against Women in Kazeroon, Islamic Republic of Iran . Violence and Victims, 25 (1), 2010.

[30] Nojomi, Marzieh and Akranmi, Z. (2012) Prrevalence of vviolence against pregnant women and effects on maternal and birth outcomes. Acta Medica Iranica. 44.

http://www.iaras.org/iaras/journals/ijems. 